\title{
Diesters Biolubricant Base Oil: Synthesis, Optimization, Characterization, and Physicochemical Characteristics
}

\author{
Jumat Salimon, Nadia Salih, and Bashar Mudhaffar Abdullah \\ School of Chemical Sciences and Food Technology, Faculty of Science and Technology, Universiti Kebangsaan Malaysia, Selangor, \\ 43600 Bangi, Malaysia \\ Correspondence should be addressed to Jumat Salimon, jumat@ukm.my
}

Received 10 September 2011; Accepted 11 October 2011

Academic Editor: Deepak Kunzru

Copyright ( 2012 Jumat Salimon et al. This is an open access article distributed under the Creative Commons Attribution License, which permits unrestricted use, distribution, and reproduction in any medium, provided the original work is properly cited.

\begin{abstract}
Diesters biolubricant base oil, oleyl 9(12)-hydroxy-10(13)-oleioxy-12(9)-octadecanoate (OLHYOOD) was synthesized based on the esterification reaction of 9,12-hydroxy-10,13-oleioxy-12-octadecanoic acid (HYOOA) with oleyl alcohol (OL) and catalyzed by sulfuric acid (SA). Optimum conditions of the experiment to obtain high yield \% of OLHYOOD were predicted at ratio of $\mathrm{OL} / \mathrm{HYOOA}$ of $2: 1 \mathrm{~mol} / \mathrm{mol}$, ratio of SA/HYOOA of $0.7: 1 \mathrm{~mol} / \mathrm{mol}$, reaction temperature $110^{\circ} \mathrm{C}$, and $7 \mathrm{~h}$ of reaction time. At this condition, the yield of OLHYOOD was $88.7 \%$. Disappearance of carboxylic acid $(\mathrm{C}=\mathrm{O})$ peak has been observed by FTIR with appearance of ester $(\mathrm{C}=\mathrm{O})$ peak at $1738 \mathrm{~cm}^{-1} \cdot{ }^{13} \mathrm{C}$, and ${ }^{1} \mathrm{H} N M R$ spectra analyses confirmed the result of OLHYOOD with the appearance of carbon-ester $(\mathrm{C}=\mathrm{O})$ chemical shift at $173.93 \mathrm{ppm}$ and at $4.05 \mathrm{ppm}$ for ${ }^{13} \mathrm{C}$ and ${ }^{1} \mathrm{H}$ NMR, respectively. The physicochemical characteristics of the OLHYOOD were also determined, which showed improved low temperature properties (PP) $-62^{\circ} \mathrm{C}$, viscosity index (VI) at 192 and also increased oxidative stability (OT) up to $215.24^{\circ} \mathrm{C}$.
\end{abstract}

\section{Introduction}

Oleochemicals that are derived from natural fats and oils are referred to as natural oleochemicals [1]. Industrially, most fatty acids are obtained from animal or vegetable sources. It is possible to produce several industrial products from fatty acids (saturated and unsaturated). Fatty acid products have different utilization as resins, plastics, perfumes, coatings, flavors, cosmetics, solvents, soaps, medicinals, biofuels, and biolubricants [2].

Synthetic biolubricant based on renewable resources are important in developing environmentally acceptable lubricating oils [3]. Currently, lubricant-based petroleum worldwide end up in the environment via total loss applications, spills, or major accidents. A fact remains that about 3 million tones are lost in the European environment every year originating from loss and high-risk lubricants mostly based on mineral oil. Emissions of mineral oil may appear to be negligible importance compared to an accident involving an oil tanker spill [4]. And also, the emissions of mineral oil arising from lubricant applications in water make lubricants contribution to the pollution of water much more significant [5].
In the last decade, a lot of interest was developed to use environmental friendly biolubricant fluids [6]. The use of environmentally acceptable vegetable-oil-based product as biolubricants has many advantages. They are nontoxic, biodegradable, derived from renewable resource and have a reasonable cost when compared to other synthetic fluids [7]. Recently, modern approaches have been adopted to solve the problems associated with application of vegetable oils in biolubricants, and some of them used for chemical modification and additive treatment [8].

Esters are known as natural lubricating oils. Besides being used as biolubricants like other ester types (diesters, trimelliate esters, dimer acid esters, phthalate esters, and polyols), fatty acid esters can also be evaluated as synthetic biolubricants [7]. The monoesters of monoalcohols are fluid liquids or solid waxes. They are used as solvents in cosmetics or biolubricants in metal treatment, textile industry, and plastics industry. Esterification is usually catalyzed by an acid catalyst donor of protons such as sulfuric acid (SA) or by a metallic catalyst [9]. 
<smiles>[R]C(=O)OC(C/C=C/CCCCC)C(O)CCCCCCCC(=O)O</smiles>

(1a)

Or<smiles>[R]C(=O)OC(CCCCC)C(O)C/C=C/CCCCCCCC(=O)O</smiles>

(1b)<smiles>[R]C(=O)OC(C/C=C/CCCCC)C(O)CCCCCCCC(=O)O[Y10]([H])=O</smiles>

(2a)<smiles>[R]OC(=O)CCCCCCC/C=C/CC(O)C(CCCCC)OC([R])=O</smiles>

(2b)

FIgURE 1: Esterification reaction of HYOOA to produce OLHYOOD. Notes: 9-hydroxy-10-oleioxy-12-octadecanoic acid (1a); 12-hydroxy13-oleioxy-9-octadecanoic acid (2a); oleyl 9-hydroxy-10-oleioxy-12-octadecanoate (1b); oleyl 12-hydroxy-13-oleioxy-9-octadecanoate (2b); oleic acid $(\mathrm{R})$ and oleyl alcohol $\left(\mathrm{R}^{\prime}\right)$.

In this study, we presents a novel synthetic approach for esterification reaction of 9(12)-hydroxy-10(13)-oleioxy12(9)-octadecanoic acid (HYOOA) with oleyl alcohol (OL) catalyzed by SA (Figure 1). It is investigated to produce diesters oleyl 9(12)-hydroxy-10(13)-oleioxy-12(9)octadecanoate (OLHYOOD) as a lubricating oil candidate to improve the physical properties of biolubricants product such as low temperature (pour point), flash point, viscosity, and oxidative stability. In this study, the esterification of HYOOA with (OL) was presented as lubricating oil for the first time. The objective of this study was to optimize process variables of esterification reaction. The process variables studied using $\mathrm{D}$-optimal design were ratio of OL/HYOOA $(\mathrm{mol} / \mathrm{mol})$, ratio of SA/HYOOA $(\mathrm{mol} / \mathrm{mol})$, reaction temperature $\left({ }^{\circ} \mathrm{C}\right)$, and reaction time (h). D-optimal design was applied to relate these four 
TABLE 1: Independent variables and their levels for D-optimal design of the esterification reaction.

\begin{tabular}{lcccc}
\hline Independent variables & & Variable Levels & +1 \\
& & -1 & 0 & 4 \\
(1) OL/HYOOA (mol/mol) & $X_{1}$ & 2 & 1 & 1.3 \\
(2) SA/HYOOA (mol/mol) & $X_{2}$ & 0.7 & 100 & 110 \\
(3) Temperature (C) & $X_{3}$ & 90 & 6 & 7 \\
(4) Time (h) & $X_{4}$ & 5 & \\
\hline
\end{tabular}

process variables with the response (diesters biolubricant yield \%).

\section{Methodology}

2.1. Experimental Procedure. The esterification reaction was carried out using oleyl alcohol (OL) and sulfuric acid (SA) as a catalyst to prepare 9(12)-hydroxy-10(13)-oleioxy-12(9)octadecanoate (OLHYOOD) [9]. Table 1 shows the different OL/HYOOA ratio, different SA/HYOOA ratio, different reaction temperature, and different reaction time using DOptimal design. Factors (variables) such as ratio OL/HYOOA $\left(\mathrm{mol} / \mathrm{mol}, X_{1}\right)$, SA/HYOOA $\left(\mathrm{mol} / \mathrm{mol}, X_{2}\right)$, reaction temperature $\left({ }^{\circ} \mathrm{C}, X_{3}\right)$, and reaction time $\left(\mathrm{h}, X_{4}\right)$ were performed under the same experimental conditions. The reactions were performed in a $250 \mathrm{~mL}$ three-neck flask equipped with a reflux condenser and a contact thermometer. The reaction mixture was heated on a magnetic heater and stirrer until it reached the experiment temperature; catalyst SA and desiccant of silica gel (SG) were added to the mixture at that moment. The reaction temperatures were held constant within a range of $\pm 1^{\circ} \mathrm{C}$. A mixture of HYOOA $(5 \mathrm{~g} ; 0.01 \mathrm{~mol})$, OL $(2: 1-4: 1 \mathrm{~mol} / \mathrm{mol})$ in a $250-\mathrm{mL}$ threeneck flask equipped with a cooler, dropping funnel and thermometer was heated for $1 \mathrm{~h}$ at $90^{\circ} \mathrm{C}$, during the $1 \mathrm{~h}$ reaction SG was put in the oven at $180^{\circ} \mathrm{C}$ for drying. After $1 \mathrm{~h} \mathrm{SG}$ drying the SG (50\% of the HYOOA) and SA $(0.7: 1-1.3: 1 \mathrm{~mol} / \mathrm{mol})$ were added to the mixture. The reaction mixture was subsequently heated to different temperatures $90-110^{\circ} \mathrm{C}$ and refluxed at different times 5$7 \mathrm{~h}$ at this temperature range. After reaction termination, the heating was stopped and the mixture was left to stand overnight at ambient temperature. After the reaction under conditions was selected as optimal, the flask was allowed to cool to room temperature. The mixture was filtered using acetic acid (AA) as a solvent to remove the SG from the product. The mixture was washed repeatedly with distilled water until all the catalysts were removed. The mixture was washed with the water and the organic layer was dried over magnesium sulphate; the solvent was removed using a vacuum evaporator. Excess OL in the mixture was removed using the distillation method. The yield \% of the ester product was determined. The FTIR and ${ }^{13} \mathrm{C},{ }^{1} \mathrm{H}$ NMR were analysed and the physicochemical properties of the product were also studied.

2.2. Experimental Design and Statistical Analysis. To explore the effect of the operation variables on the response in the region of investigation, a $\mathrm{D}$-optimal design was performed [10]. Ratio of OL/HYOOA ( $\left.\mathrm{mol} / \mathrm{mol}, X_{1}\right)$, ratio of $\mathrm{SA} / \mathrm{HYOOA}\left(\mathrm{mol} / \mathrm{mol}, X_{2}\right)$, reaction temperature $\left({ }^{\circ} \mathrm{C}, X_{3}\right)$, and reaction time $\left(h, X_{4}\right)$ were selected as independent variables. The range of values and coded levels of the variables are given in Table 1. A polynomial equation was used to predict the response as a function of independent variables and their interactions. In this work, the number of independent variables was three and therefore the response for the quadratic polynomials becomes

$$
Y=\beta_{0}+\sum \beta_{i} x_{i}+\sum \beta_{i i} x_{i}^{2}+\sum \sum \beta_{i j} x_{i} x_{j},
$$

where $\beta_{0}, \beta_{i}, \beta_{i i}$, and $\beta_{i j}$ are constant, linear, square and interaction regression coefficient terms, respectively, and $x_{i}$ and $x_{j}$ are independent variables. The Minitab software version 14 (Minitab Inc., USA) was used for multiple regression analysis, analysis of variance (ANOVA), and analysis of ridge maximum of data in the response surface regression (RSREG) procedure. The goodness of fit of the model was evaluated by the coefficient of determination $R^{2}$ and its statistical significance that was checked by the $F$-test.

\subsection{Physicochemical Characteristics}

2.3.1. FTIR and ${ }^{1} \mathrm{H},{ }^{13} \mathrm{C}$ NMR. FTIR of the products was recorded on a Perkin Elmer Spectrum GX spectrophotometer in the range $650-4000 \mathrm{~cm}^{-1}$. A very thin film of the sample was applied to $\mathrm{NaCl}$ cells $(25 \mathrm{~mm}$ i.d $\times 4 \mathrm{~mm}$ thickness) for analysis. ${ }^{1} \mathrm{H}$ and ${ }^{13} \mathrm{C}$ NMR spectra were recorded using a JEOL JNM-ECP 400 spectrometer operating at a frequency of 400.13 and $100.77 \mathrm{MHz}$, respectively, using a $5 \mathrm{~mm}$ broadband inverse $Z$-gradient probe in DMSO-d6 (Cambridge Isotope Laboratories, Andover, MA) as solvent. Each spectrum was Fourier-transformed, phase-corrected, and integrated using MestRe-C 2.3a (Magnetic Resonance Companion, Santiago de Compostela, Spain) software [9].

2.3.2. Low Temperature Operability. Pour point (PP) values were measured according to the American National Standard Method using $U$-tube tester (ASTM D5949 method) [9].

2.3.3. Flash Point Values. Flash point (FP) determination was run according to the American National Standard Method using a Tag Closed Tester (ASTM D 56-79) [9].

2.3.4. Viscosity Index Measurements. Viscosity Index Monitor HV M472 obtained from Walter Herzog (Germany) 
TABLE 2: D-optimal design arrangement and yield \% response of OLHYOOD.

\begin{tabular}{|c|c|c|c|c|c|}
\hline \multirow{3}{*}{ Run no. } & \multicolumn{4}{|c|}{ Coded independent variable levels } & \multirow{3}{*}{$\begin{array}{c}\text { Response } \\
\text { Yield }^{\mathrm{d}} \\
(\%, Y)\end{array}$} \\
\hline & $\mathrm{OL}^{\mathrm{a}} / \mathrm{HYOOA}^{\mathrm{b}}$ & $\mathrm{SA}^{\mathrm{c}} / \mathrm{HYOOA}$ & Temperature & & \\
\hline & $\left(\mathrm{mol} / \mathrm{mol}, X_{1}\right)$ & $\left(\mathrm{mol} / \mathrm{mol}, X_{2}\right)$ & $\left({ }^{\circ} \mathrm{C}, X_{3}\right)$ & $\left(\mathrm{h}, X_{4}\right)$ & \\
\hline 1 & 2 & 0.70 & 90 & 5 & 38.7 \\
\hline 2 & 2 & 1.30 & 110 & 7 & 66.7 \\
\hline 3 & 2 & 1.30 & 110 & 7 & 78.3 \\
\hline 4 & 4 & 1.00 & 100 & 6 & 45.7 \\
\hline 5 & 3 & 1.15 & 100 & 6 & 41.5 \\
\hline 6 & 2 & 1.00 & 90 & 7 & 75.9 \\
\hline 7 & 4 & 1.00 & 90 & 5 & 47.5 \\
\hline 8 & 4 & 1.00 & 110 & 7 & 84.4 \\
\hline 9 & 4 & 0.70 & 110 & 5 & 45.9 \\
\hline 10 & 4 & 0.70 & 110 & 5 & 50.1 \\
\hline 11 & 2 & 1.30 & 90 & 5 & 43.1 \\
\hline 12 & 2 & 1.30 & 90 & 5 & 46.4 \\
\hline 13 & 2 & 0.70 & 110 & 7 & 88.7 \\
\hline 14 & 4 & 1.30 & 110 & 6 & 60.2 \\
\hline 15 & 3 & 1.30 & 110 & 5 & 44.5 \\
\hline 16 & 2 & 0.70 & 110 & 7 & 51.5 \\
\hline 17 & 3 & 0.70 & 100 & 6 & 58.1 \\
\hline 18 & 2 & 1.00 & 110 & 5 & 68.2 \\
\hline 19 & 4 & 1.30 & 90 & 7 & 78.3 \\
\hline 20 & 4 & 0.70 & 90 & 7 & 55.7 \\
\hline 21 & 3 & 1.00 & 110 & 6 & 76.7 \\
\hline 22 & 2 & 1.00 & 100 & 6 & 65.9 \\
\hline 23 & 3 & 1.00 & 90 & 6 & 69.5 \\
\hline 24 & 4 & 1.30 & 100 & 5 & 50.8 \\
\hline 25 & 4 & 1.30 & 90 & 7 & 72.3 \\
\hline
\end{tabular}

Notes: oleyl alcohol (a); 9(12)-hydroxy-10(13)-oleioxy-12(9)-octadecanoic acid (HYOOA) (b); sulfuric acid (c); yield \% of oleyl 9(12)-hydroxy-10(13)oleioxy-12(9)-octadecanoate (OLHYOOD) (d).

was used to measure viscosity. Measurements were run in a Temp-Trol (Precision Scientific, Chicago, IL, USA) viscometer bath set at 40.0 and $100.0^{\circ} \mathrm{C}$. The viscosity and viscosity index were calculated using ASTM method ASTM D 2270-93 [9], respectively.

2.3.5. Oxidative Stability. Pressurized DSC (PDSC) experiments were accomplished using a DSC 2910 thermal analyzer from TA Instruments (Newcastle, DE) [9]. Typically, a 2-1L sample, resulting in a film thickness of $<1 \mathrm{~mm}$, was placed in an aluminum pan hermetically sealed with a pinhole lid and oxidized in the presence of dry air (Gateway Airgas, St. Louis, $\mathrm{MO}$ ), which was pressurized in the module at a constant pressure of $1378.95 \mathrm{kPa}(200 \mathrm{psi})$. A $10^{\circ} \mathrm{C} \mathrm{min}^{-1}$ heating rate from 50 to $350^{\circ} \mathrm{C}$ was used during each experiment. The oxidation onset $\left(\mathrm{OT},{ }^{\circ} \mathrm{C}\right)$ was calculated from a plot of heat flow $(\mathrm{W} / \mathrm{g})$ versus temperature for each experiment.

\section{Results and Discussion}

3.1. Effect of Process Parameters and Statistical Analysis. Diesters biolubricant oleyl 9(12)-Hydroxy-10(13)-oleioxy12(9)-octadecanoate (OLHYOOD) was synthesized from direct esterification of HYOOA, where the corresponding HYOOA react with OL in the presence of a suitable catalyst such as sulfuric acid (SA). The acid catalysts are the most common catalysts used in biolubricant industry because the process provides faster reaction conditions and moderate compared to the alkali catalyst [9].

In the present study, biolubricant production using homogeneous acid-catalyzed esterification process SA was proposed. The influence of the ratio of OL/HYOOA $\left(2: 1-4: 1 \mathrm{~mol} / \mathrm{mol} ; X_{1}\right)$, ratio of SA/HYOOA $(0.7: 1-$ $\left.1.3: 1 \mathrm{~mol} / \mathrm{mol} ; X_{2}\right)$, reaction temperature $\left(90-110^{\circ} \mathrm{C} ; X_{3}\right)$, and reaction time $\left(5-7 \mathrm{~h} ; X_{4}\right)$ to the esterification reaction was studied Table 2 . The process variables were optimized 
TABLE 3: Regression coefficients of the predicted quadratic polynomial model for response variables of the yield \% of OLHYOOD.

\begin{tabular}{lccc}
\hline Variables & Coefficients $(\beta)$, yield \% of OLHYOOD $(Y)$ & $T$ & $P$ \\
\hline Linear & & & 0.7286 \\
$X_{1}$ & -1.67 & 0.12 & 0.5334 \\
$X_{2}$ & 2.50 & 0.40 & 0.2594 \\
$X_{3}$ & 3.99 & 1.35 & 0.0002 \\
$X_{4}$ & 10.83 & 19.83 & \\
Quadratic & & & 0.9474 \\
$X_{11}$ & -0.59 & $4.580 \mathrm{E}-003$ & 0.1512 \\
$X_{22}$ & -9.66 & 2.41 & 0.3775 \\
$X_{33}$ & 7.96 & 0.85 & 0.9302 \\
$X_{44}$ & 0.90 & $8.067 \mathrm{E}-003$ & \\
Interaction & & & 0.5149 \\
$X_{12}$ & 2.49 & 0.46 & 0.9245 \\
$X_{13}$ & -0.36 & $9.453 \mathrm{E}-003$ & 0.8069 \\
$X_{14}$ & 0.92 & 0.063 & 0.4574 \\
$X_{23}$ & -2.85 & 0.60 & 0.6624 \\
$X_{24}$ & 1.69 & 0.20 & 0.7116 \\
$X_{34}$ & -1.40 & 0.14 & \\
$R^{2}$ & 0.69 & & \\
\hline
\end{tabular}

Notes: $X_{1}=\mathrm{OL} / \mathrm{HYOOA} ; X_{2}=\mathrm{SA} / \mathrm{HYOOA} ; X_{3}=$ reaction temperature; $X_{4}=$ reaction time.

${ }^{* *} P<0.05$; ${ }^{* * *} P<0.01$. $T$ : $F$ test value.

See Table 2 for a description of the abbreviations.

TABLE 4: Analysis of variance (ANOVA) for $Y$ response of OLHYOOD.

\begin{tabular}{lccccc}
\hline Source & $D f$ & Sum of squares & Mean square & F value & Prob $>$ F \\
\hline Model & 4 & 2828.18 & 707.05 & 5.60 & 0.0034 \\
Residual & 20 & 2523.33 & 126.17 & & Significant \\
Lack-of-fit & 15 & 1731.87 & 115.46 & 0.73 & 0.7102 \\
Pure error & 5 & 791.47 & 158.49 & & Not significant \\
\hline
\end{tabular}

using the D-optimal design in obtaining the maximum yield \% of biolubricant $Y$. This method was also applied to determine the significance and interaction of the variables affecting the diesters biolubricant production. Results obtained from the observed experiments are summarized in Table 2. The results developed a second-order polynomial equation that could relate diesters biolubricant yield to the parameters study. The following quadratic model was explained in (2) [10]

$$
\begin{aligned}
Y= & +59.19-1.67 X_{1}+2.50 X_{2}+3.99 X_{3}+10.83 X_{4} \\
& -0.59 X_{1}^{2}-9.66 X_{2}^{2}+7.96 X_{3}^{2}+0.90 X_{4}^{2}+2.49 X_{1} X_{2} \\
& -0.36 X_{1} X_{3}+0.92 X_{1} X_{4}-2.85 X_{2} X_{3}+1.69 X_{2} X_{4} \\
& -1.40 X_{3} X_{4} .
\end{aligned}
$$

Table 2 illustrates the yield \% effect related with alcohol, catalyst, reaction temperature, and reaction time. As expected, at high temperature $\left(110^{\circ} \mathrm{C}\right)$ and long time $(7 \mathrm{~h})$ showed high yield at about $88.7 \%$ compared with temperatures of 90 and $100^{\circ} \mathrm{C}$. As described in the mechanism, most of the carboxylic acid groups were consequently converted into and ester bonds in the molecule. The decrease of biolubricant yield \% at a higher reaction temperature and longer time was probably as a result of losing OL due to the fact that it did not condense effectively at a higher temperature as the boiling point of $\mathrm{OL}$ is $107^{\circ} \mathrm{C}$ [11].

The quadratic regression coefficient obtained by employing a least squares method technique to predict quadratic polynomial models for the yield $\%(Y)$ of OLHYOOD are given in Table 3 . The yield \% of OLHYOOD $(Y)$, the linear term of reaction time $\left(X_{4}\right)$ was high significant $(P<0.01)$.

The lack of fit $F$-value for the $Y$ response showed that the lack of fit is not significant $(P>0.05)$ relative to the pure error. This indicates that all the models predicted for the $Y$ response were adequate. Regression models for data on response $Y$ was significant $(P<0.05)$ with satisfactory $R^{2}$. However, the predicted values match the observed values reasonably well, with $R^{2}$ of 0.69 , and the model was significant. Table 4 summarizes the analysis of variance (ANOVA) for the response of this study.

Figures 2(a) and 2(b) are the Design-Expert plots for all the responses. In the diesters biolubricant reaction of OLHYOOD, performing the technique using high-reaction temperature and long time would give the desired yield \% of OLHYOOD as shown in Figure 2. The biolubricant yield $\%$ increased as the reaction time increased to its high level 


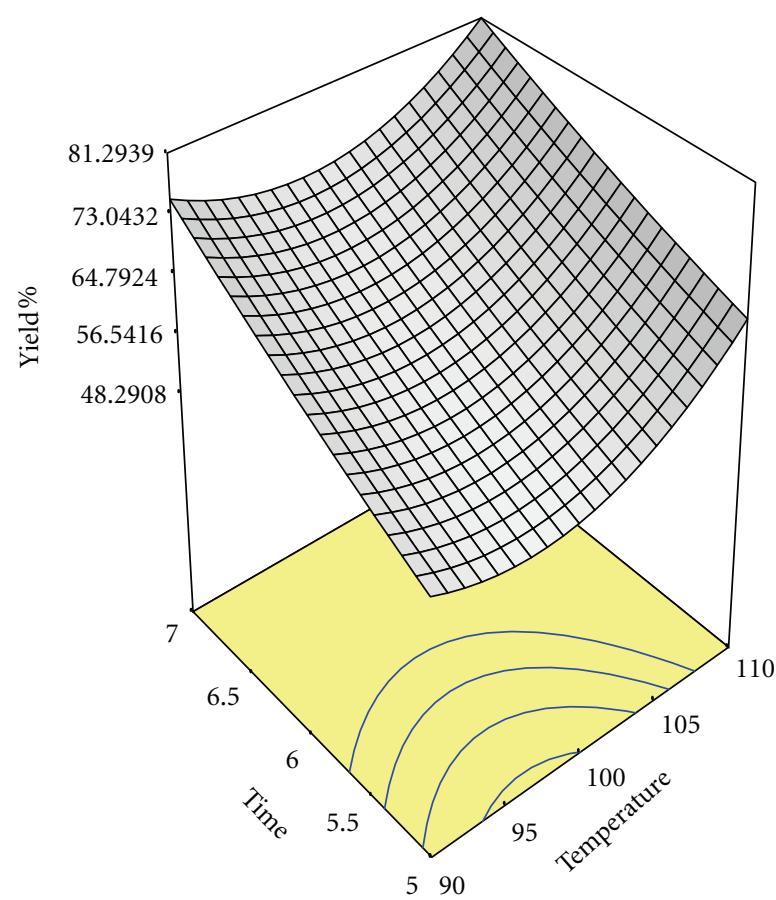

(a)

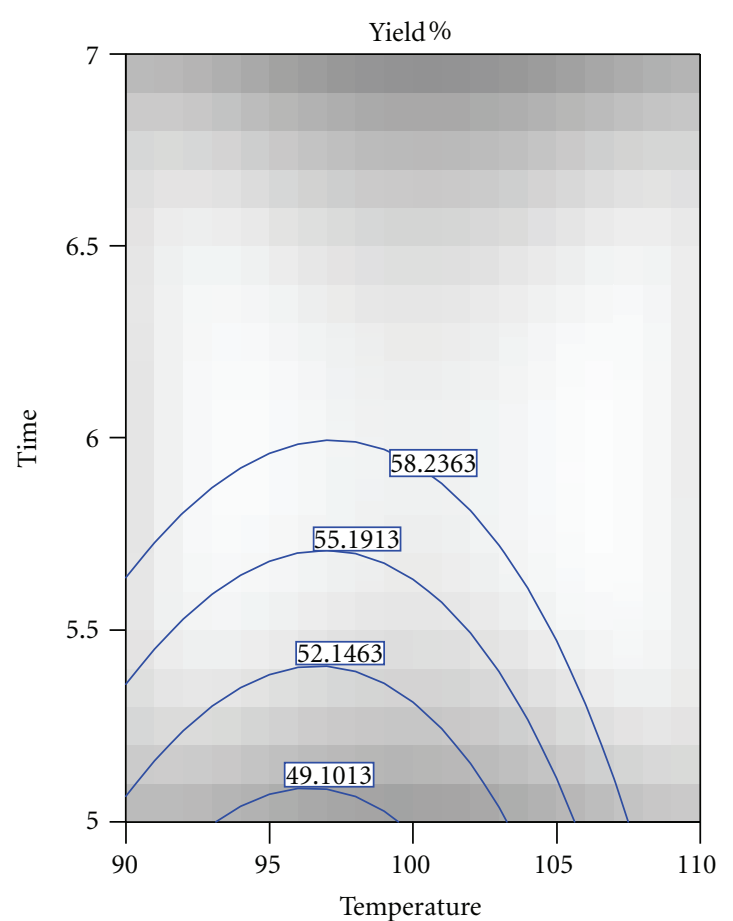

(b)

Figure 2: Response surface (a) and contour plots (b) for the effect of reaction temperature $\left(X_{3},{ }^{\circ} \mathrm{C}\right)$ and reaction time $\left(X_{4}, \mathrm{~h}\right)$ on the yield $(Y, \%)$ of OLHYOOD.

TABLE 5: The main wavelengths in FTIR functional groups of HYOOA and OLHYOOD.

\begin{tabular}{lcc}
\hline Wavelength of HYOA $^{\mathrm{a}}$ & Wavelength of OLHYOOD & Functional groups \\
\hline 3413 & 3445 & OH stretching (alcohol) \\
3003 & 3003 & C=C bending vibration (aliphatic) \\
2925,2855 & 2925,2554 & C-H stretching vibration (aliphatic) \\
1737 & 1738 & C=O stretching vibration (ester) \\
1711 & - & C=O stretching vibration (carboxylic acid) \\
1461 & 1461 & C-H scissoring and bending for methylene group \\
1176,1117 & 1173,1117 & C-O stretching vibration (ester) \\
1279 & - & C-O stretching assymmetric (carboxylic acid) \\
967 & 967 & C-H bending vibration (alkene) \\
723 & 723 & C-H group vibration (aliphatic) \\
\hline
\end{tabular}

Notes: 9(12)-hydroxy-10(13)-oleioxy-12(9)-octadecanoic acid (a); oleyl 9(12)-hydroxy-10(13)-oleioxy-12(9)-octadecanoate (b).

(7 h). The biolubricant yield \% also increased with reaction temperature to its high level $\left(110^{\circ} \mathrm{C}\right)$, and the stronger influence of reaction time occurred when reaction time was at its high level. The relationships between the parameters and yield \% of OLHYOOD were linear or almost linear (Figure 2).

Optimum conditions of the experiment to obtain high yield $\%$ of OLHYOOD were predicted at ratio of OL/HYOOA of $2: 1 \mathrm{~mol} / \mathrm{mol}$, ratio of SA/HYOOA of $0.7: 1 \mathrm{~mol} / \mathrm{mol}$, reaction temperature $110^{\circ} \mathrm{C}$, and reaction time $7 \mathrm{~h}$. At this condition, the yield \% of OLHYOOD was $88.7 \%$. The observed value was reasonably close to the predicted value as shown in Figure 3. Experimental variables should be carefully controlled in order to obtain reasonable yield.
3.2. FTIR Analysis of OLHYOOD. The spectrum from the FTIR analysis displays several absorption peaks as shown in Figure 4. The main peaks and their assignment to functional groups are given in Table 5. FTIR peaks of OLHYOOD indicated disappearance of absorption band at $1711 \mathrm{~cm}^{-1}$ which belongs to the $\mathrm{C}=\mathrm{O}$ carboxylic acid, while it appears in HYOOA. For the ester carbonyl functional groups $\mathrm{C}=\mathrm{O}$ at $1737 \mathrm{~cm}^{-1}$ of OLHYOOD which showed the same absorption band in HYOOA at $1738 \mathrm{~cm}^{-1}$.

FTIR Peaks at 2925 to $2855 \mathrm{~cm}^{-1}$ indicated the $\mathrm{CH}_{2}$ and $\mathrm{CH}_{3}$ scissoring of HYOOA and OLHYOOD. The FTIR spectroscopy analysis of HYOOA and OLHYOOD indicated the presence of peak at $3003 \mathrm{~cm}^{-1}$ which belongs to the double bond $\mathrm{C}=\mathrm{C}$ (stretching aliphatic), while at 3445 and 
TABLE 6: The main signals present in ${ }^{13} \mathrm{C}$ NMR functional groups of HYOOA and OLHYOOD.

\begin{tabular}{lcc}
\hline$\delta(\mathrm{ppm})$ of HYOA $^{\mathrm{a}}$ & $\delta(\mathrm{ppm})$ of OLHYOOD & Assignment \\
\hline $25.76-34.38$ & $25.75-34.37$ & Aliphatic Carbons \\
64.41 & 64.37 & $-\mathrm{OH}$ Alcohol \\
$127.90-130.57$ & $129.61-130.46$ & $-\mathrm{CH}=\mathrm{CH}-$ Olefinic carbons \\
174.01 & 173.93 & $\mathrm{C}=\mathrm{O}$ Ester \\
178.11 & - & C=O Carboxylic acid \\
\hline
\end{tabular}

Notes: 9,12-hydroxy-10,13-oleioxy-12,9-octadecanoic acid (a); 9(12)-hydroxy-10(13)-oleioxy-12(9)-octadecanoate (b).

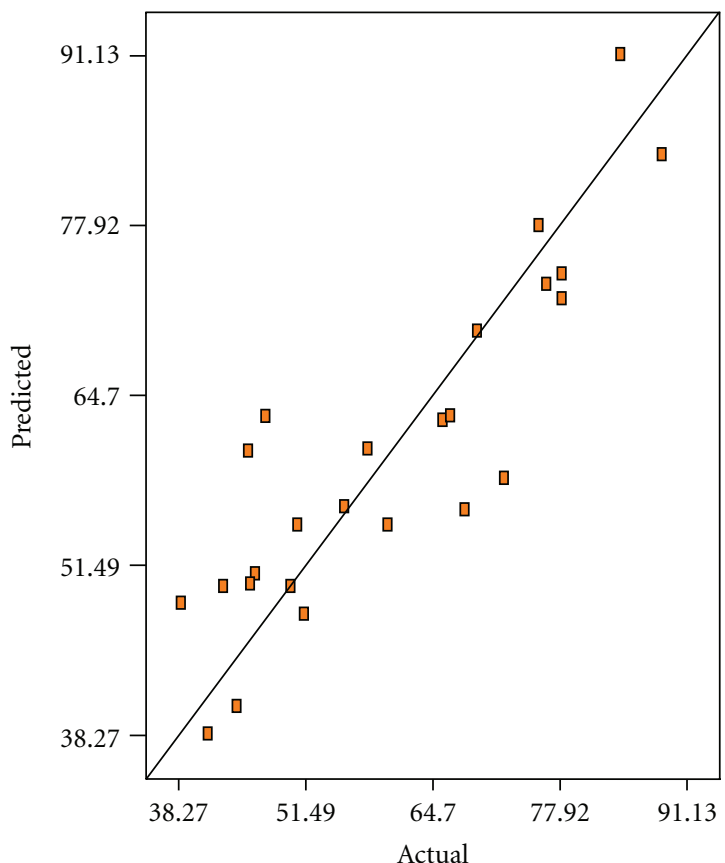

Figure 3: Predicated versus actual plot of $Y$ (OLHYOOD).

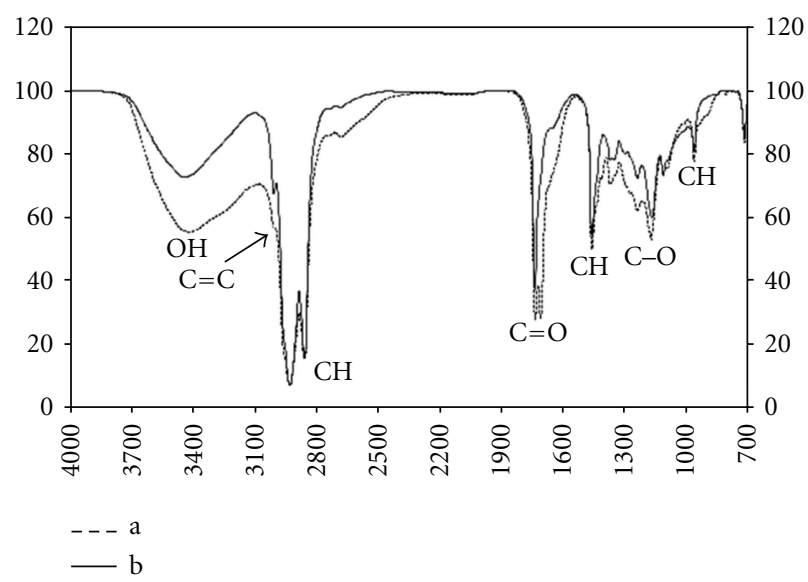

FIgURE 4: FTIR spectrum of the HYOOA (a) and OLHYOOD (b).

$3413 \mathrm{~cm}^{-1}$ it belongs to $-\mathrm{OH}$ stretching of OLHYOOD and HYOOA, respectively.

The peaks at 1176,1173 , and $1117 \mathrm{~cm}^{-1}$ of HYOOA and OLHYOOD are referred to as $\mathrm{C}-\mathrm{O}$ stretching ester. FTIR spectrum also showed absorption bands at $723 \mathrm{~cm}^{-1}$ of $\mathrm{C}-\mathrm{H}$

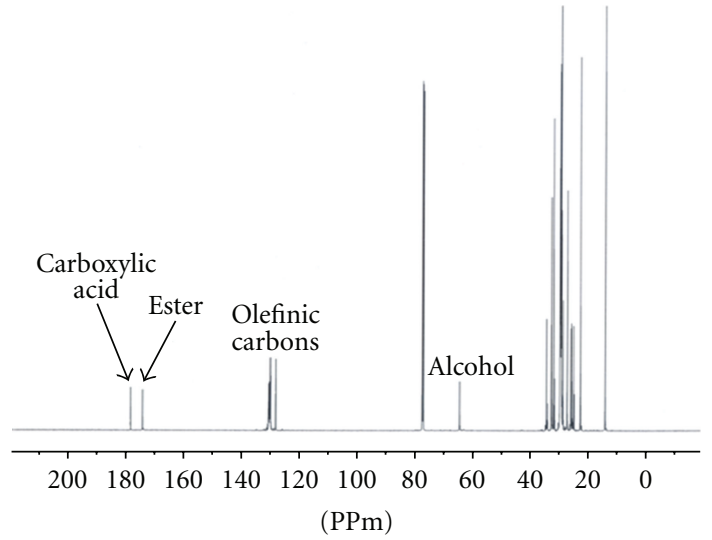

(a)

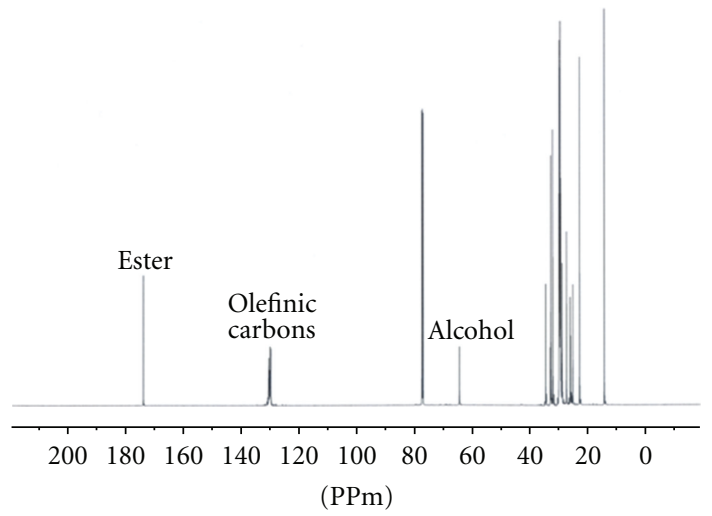

(b)

FIGURE 5: ${ }^{13} \mathrm{C}$ NMR spectrum of HYOOA (a) and OLHYOOD (b).

group vibration. A similar observation has been reported for the FTIR spectrum of other studies [9].

\section{3. ${ }^{13} \mathrm{C}$ and ${ }^{1} \mathrm{H}$ NMR Analysis of OLHYOOD}

3.3.1. ${ }^{13} \mathrm{C}$ NMR Analysis. Figures 5(a) and 5(b) indicates the ${ }^{13} \mathrm{C}$ NMR spectrum of HYOOA and OLHYOOD, respectively. The ${ }^{13} \mathrm{C}$ spectroscopy shows the main signals assignment of HYOOA and OLHYOOD as shown in Table 6. Figure 5(b) showed disappearance of carbon atom of the carbonyl group (carboxylic acid) of OLHYOOD which has appeared for HYOOA at $178.11 \mathrm{ppm}$, while at 173.93 $174.01 \mathrm{ppm}$ it has appeared in OLHYOOD and HYOOA which refer to ester group. The signals at 127.90 to 
TABLE 7: The main signals present in ${ }^{1} \mathrm{H}$ NMR functional groups of HYOOA and OLHYOOD.

\begin{tabular}{lcc}
\hline$\delta(\mathrm{ppm})$ of $\mathrm{HYOOA}^{\mathrm{a}}$ & $\delta(\mathrm{ppm})$ of OLHYOOD & Assignment \\
\hline $0.82-0.84$ & $0.86-0.88$ & $-\mathrm{CH}_{3}$ \\
$1.23-2.06$ & $1.25-2.01$ & $-\mathrm{CH}_{2}$ \\
$2.26-2.33$ & $2.26-2.29$ & $-\mathrm{CH}$ \\
3.62 & 3.62 & $-\mathrm{CHOH}$ \\
4.06 & 4.05 & $-\mathrm{CHOCOR}$ \\
$5.31-5.40$ & $5.33-5.37$ & $-\mathrm{CH}=\mathrm{CH}-$ \\
\hline
\end{tabular}

Notes: 9,12-hydroxy-10,13-oleioxy-12,9-octadecanoic acid (a); 9(12)-hydroxy-10(13)-oleioxy-12(9)-octadecanoate (b).

$130.74 \mathrm{ppm}$ refer to the unsaturated carbon atoms (olefinic carbons) for both HYOOA and OLHYOOD.

Figures 5(a) and 5(b) can confirm the appearance of $\mathrm{OH}$ alcohol of OLHYOOD and HYOOA at about 64.37 and $64.41 \mathrm{ppm}$, respectively. The other distinctive signals were aliphatic carbons for OLHYOOD and HYOOA at about 25.76-34.38 ppm which are common for these types of compounds belonging to the methylene carbon atoms of HYOOA and OLHYOOD [9].

3.3.2. ${ }^{1} \mathrm{H}$ NMR Analysis. The ${ }^{1} \mathrm{H}$ NMR spectroscopy shows the main signals assignments in HYOOA and OLHYOOD as shown in Table 7 . The results show the distinguishable peaks that appeared in OLHYOOD and HYOOA for - $\mathrm{CH}-$ $\mathrm{OH}$ at $3.62 \mathrm{ppm}$ while $-\mathrm{CHOCOR}$ at 4.06 and $4.05 \mathrm{ppm}$ as shown in Figures 6(a) and 6(b), respectively. The signals at $0.82-0.88 \mathrm{ppm}$ referred to the methylene group $\left(-\mathrm{CH}_{3}\right)$ of OLHYOOD which also appear in HYOOA next to the terminal methyl $\left(-\mathrm{CH}_{2}\right)$ at $1.23-2.06 \mathrm{ppm}$ of OLHYOOD and HYOOA. The other distinctive signals were those of methine at about $2.26-2.33 \mathrm{ppm}$, which are common for these types of compounds [12]. However, the methane proton signals $(-\mathrm{CH}=\mathrm{CH}-)$ were shifted upfield at about 5.33-5.37 ppm of OLHYOOD [9].

3.4. Physicochemical Characteristics. The physicochemical characteristics of OLHYOOD compound are summarized in Table 8 , in an effective way to introduce branching on the fatty acid (FA) chain. The branched product has significantly improved the pour point (PP), flash point (FP), viscosity index (VI), and higher oxidative stability (OT) comparing HYOOA with other diesters compounds such as IBHYBOD [9].

Esterification reaction improved the $\mathrm{PP}$ at $-62^{\circ} \mathrm{C}$ significantly of OLHYOOD (Table 8) compared with last step $\mathrm{HYOOA}$ at $51^{\circ} \mathrm{C}$ and with IBHYBOD at $-60^{\circ} \mathrm{C}$. Attachment of OL to produce OLHYOOD was the most effective decreasing the PP to -62 . It can be assumed that the presence of a large branching point on the fatty acid ester creates a steric barrier around the individual molecules and inhibits crystallization, resulting in lower PP [13]. Table 8 has shown the improvement in FP of OLHYOOD which increased to $264^{\circ} \mathrm{C}$ compared with $251^{\circ} \mathrm{C}$ of $\mathrm{HYOOA}$, which means that the result agrees with the various international standards that the biolubricants FP are combustible with higher than $43^{\circ} \mathrm{C}$.

From the VI data of compounds HYOOA 153 and OLHYOOD 192 (Table 8), the result showed that VI increases

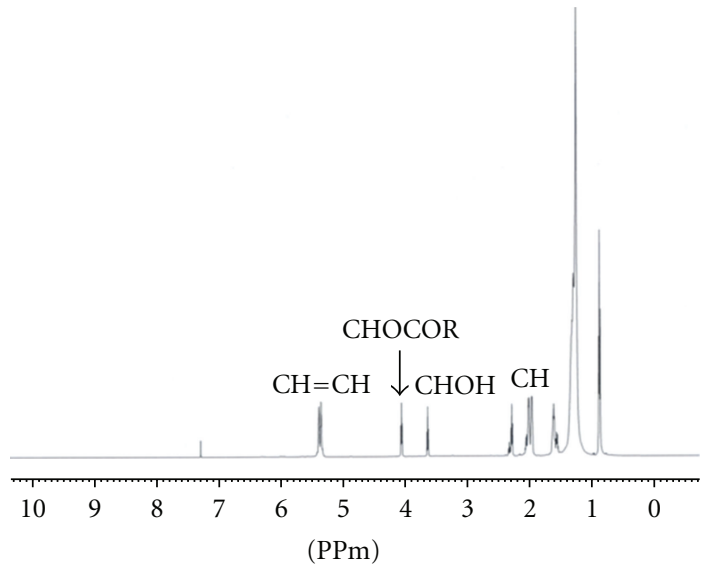

(a)

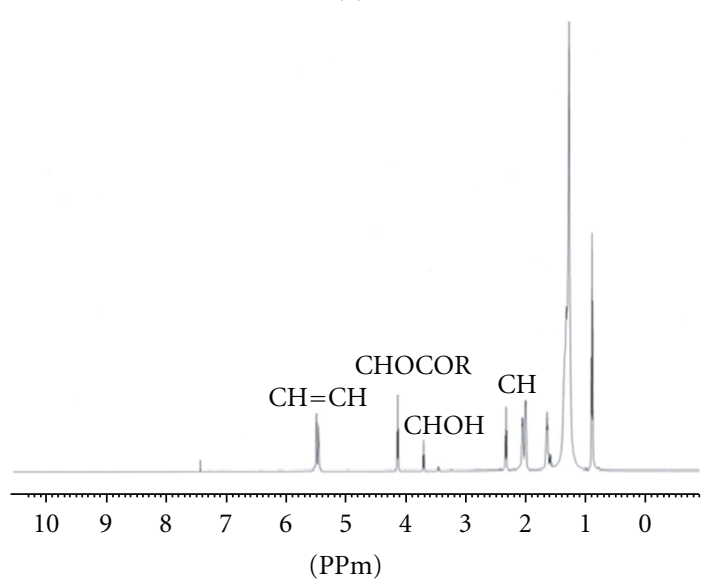

(b)

Figure 6: ${ }^{1} \mathrm{H}$ NMR spectrum of HYOOA (a) and OLHYOOD (b).

with increasing chain length (number of carbons), which the result of OLHYOOD higher than other compound such as IBHYBOD 123. A high VI indicates small viscosity changes with temperature. Therefore, it is expected that biolubricant oil that has a high VI can cause a very little change in viscosity with temperature extremes and is considered to have a stable viscosity temperature relation [14].

In this study, using OL for esterification of HYOOA which significantly improves the oxidation stability (OT) for OLHYOOD at $215.24^{\circ} \mathrm{C}$ (Figure 7 ) more than oxirane ring opening compound HYOOA at $180.94^{\circ} \mathrm{C}$ and both these 
TABLE 8: Physicochemical characteristics of OLHYOOD.

\begin{tabular}{lccc}
\hline Properties & HYOOA $^{\text {a }}$ & OLHYOOD $^{\text {b }}$ & IBHYBOD $^{\mathrm{c}}$ \\
\hline Pour point $\left({ }^{\circ} \mathrm{C}\right)$ & -51 & -62 & -60 \\
Flash point $\left({ }^{\circ} \mathrm{C}\right)$ & 251 & 264 & 297 \\
Viscosity at $40^{\circ} \mathrm{C}(\mathrm{cSt})$ & 324.5 & 136.5 & - \\
Viscosity at $100^{\circ} \mathrm{C}(\mathrm{cSt})$ & 33.05 & 22.3 & - \\
Viscosity Index $\left({ }^{\circ} \mathrm{C}\right)$ & 153 & 192 & 123 \\
Oxidative stability OT $\left({ }^{\circ} \mathrm{C}\right)$ & 180.24 & 215.24 & 64 \\
\hline
\end{tabular}

Notes: 9(12)-hydroxy-10(13)-oleioxy-12(9)-octadecanoic acid (a); oleyl 9(12)-hydroxy-10(13)-oleioxy-12(9)-octadecanate (b); isobutyl 9-hydroxy-10behenoxyoctadecanate [7] (c).

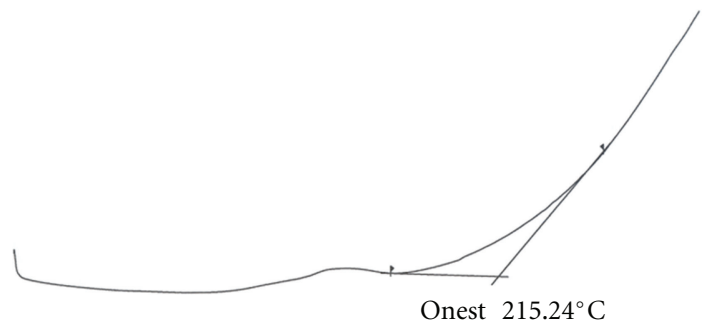

$40 \quad 60 \quad 80 \quad 100120140160180200220240260280$

$\left({ }^{\circ} \mathrm{C}\right)$

FIgURE 7: Differential scanning calorimetry oxidation stability curve of OLHYOOD.

compound OLHYOOD and HYOOA are higher in oxidation stability than in (see other studies such as IBHYBOD at $64^{\circ} \mathrm{C}$ which is prepared [9] Table 8). These results are in agreement with other studies on synthetic esters; the oxidative stability increased with increasing chain length of the esterified FA [15]. At high OT would suggest a high oxidation stability of OLHYOOD.

\section{Conclusion}

The results show that the optimum conditions of the experiment to obtain high yield $\%$ of OLHYOOD were predicted at ratio of OL/HYOOA of $2: 1 \mathrm{~mol} / \mathrm{mol}$, ratio of SA/HYOOA of $0.7: 1 \mathrm{~mol} / \mathrm{mol}$, reaction temperature $110^{\circ} \mathrm{C}$, and $7 \mathrm{~h}$ of reaction time. At this condition, the yield of OLHYOOD was $88.7 \%$. Based on the results obtained, an increase in the molecular weight of the OLHYOOD had a positive influence on the low temperature properties PP $-62^{\circ} \mathrm{C}$ of the biolubricant product. The results have shown the improvement in FP, which increased to $264^{\circ} \mathrm{C}$. The VI increased up to 192 and also the OT increased to $215.24^{\circ} \mathrm{C}$ due to high molar weight, and especially the altered structure of their molecules.

\section{Acknowledgment}

The authors thank UKM and the Ministry of Science and Technology for research Grants UKM-GUP-NBT-08-27-113 and UKM-OUP-NBT-29-150/2011.

\section{References}

[1] A. J. Kaufmann and R. J. Ruebusch, "Oleochemicals-A look at world trends," INFORM, vol. 1, pp. 1034-1048, 1990.

[2] N. O. V. Sonntag, "Composition and characteristics of individual fats and oils," in Bailey's Industrial Oil and Fat Products, M. W. Swern, Ed., pp. 289-478, John Wiley \& Sons, New York, NY, USA, 1979.

[3] D. Hörner, "Recent trends in environmentally frinedly lubricants," Journal of Synthetic Lubrication, vol. 18, no. 4, pp. 327347, 2002.

[4] H. Ridderikhoff, "Safety, health and environmental considerations in the selection and development of base-fluids for industrial lubricants," in Proceedings of the 15th Annual General Meeting of the ELGI in Vienna, April 2003.

[5] P. Broekhuizen, D. Thodori, K. L. Blansch, and S. Ullmer, Lubrication in Inland and Costal Water Activities, Taylor \& Francis, Amsterdam, The Netherland, 2003.

[6] L. R. Rudnick and S. Z. Erhan, "Natural oils as lubricants," in Synthetics, Mineral Oils, and Bio-Based Lubricants, L. R. Rudnick, Ed., pp. 353-360, CRC \& Taylor \& Francis, Boca Raton, Fla, USA, 2006.

[7] A. Özgülsün, F. Karasmanoglu, and M. Tüter, "Esterification reaction of oleic acid with a fusel oil fraction for production of lubricating oil," JAOCS, vol. 77, no. 1, pp. 105-109, 2000.

[8] S. Z. Erhan, "Vegetable oils as lubricants, hydraulic fluids, and inks," in Bailey's Industrial Oil and Fat Products, F. Shahidi, Ed., John Wiley \& Sons, Hoboken, NJ, USA, 6th edition, 2005.

[9] J. Salimon, N. Salih, and E. Yousif, "Chemically modified biolubricant basestocks from epoxidized oleic acid: improved low temperature properties and oxidative stability," Journal of Saudi Chemical Society, vol. 15, pp. 195-201, 2010.

[10] M. Wu, H. Ding, S. Wang, and S. Xu, "Optimizing conditions for the purification of linoleic acid from sunflower oil by urea complex fractionation," JAOCS, vol. 85, no. 7, pp. 677-684, 2008.

[11] N. Razali, H. Mootabadi, B. Salamatinia, K. T. Lee, and A. Z. Abdullah, "Optimization of process parameters for alkalinecatalysed transesterification of palm oil using response surface methodology," Sains Malaysiana, vol. 39, no. 5, pp. 805-809, 2010.

[12] K. M. Doll, B. K. Sharma, and S. Z. Erhan, "Synthesis of branched methyl hydroxy stearates including an ester from bio-based levulinic acid," Industrial and Engineering Chemistry Research, vol. 46, no. 11, pp. 3513-3519, 2007.

[13] B. K. Sharma, K. M. Doll, and S. Z. Erhan, "Ester hydroxy derivatives of methyl oleate: tribological, oxidation and low temperature properties," Bioresource Technology, vol. 99, no. 15, pp. 7333-7340, 2008. 
[14] H. S. Hwang, A. Adhvaryu, and S. Z. Erhan, "Preparation and properties of lubricant basestocks from epoxidized soybean oil and 2-ethylhexanol," JAOCS, vol. 80, no. 8, pp. 811-815, 2003.

[15] H. Kubouchi, H. Kai, K. Miyashita, and K. Matsuda, "Effects of emulsifiers on the oxidative stability of soybean oil TAG in emulsions," JAOCS, vol. 79, no. 6, pp. 567-570, 2002. 

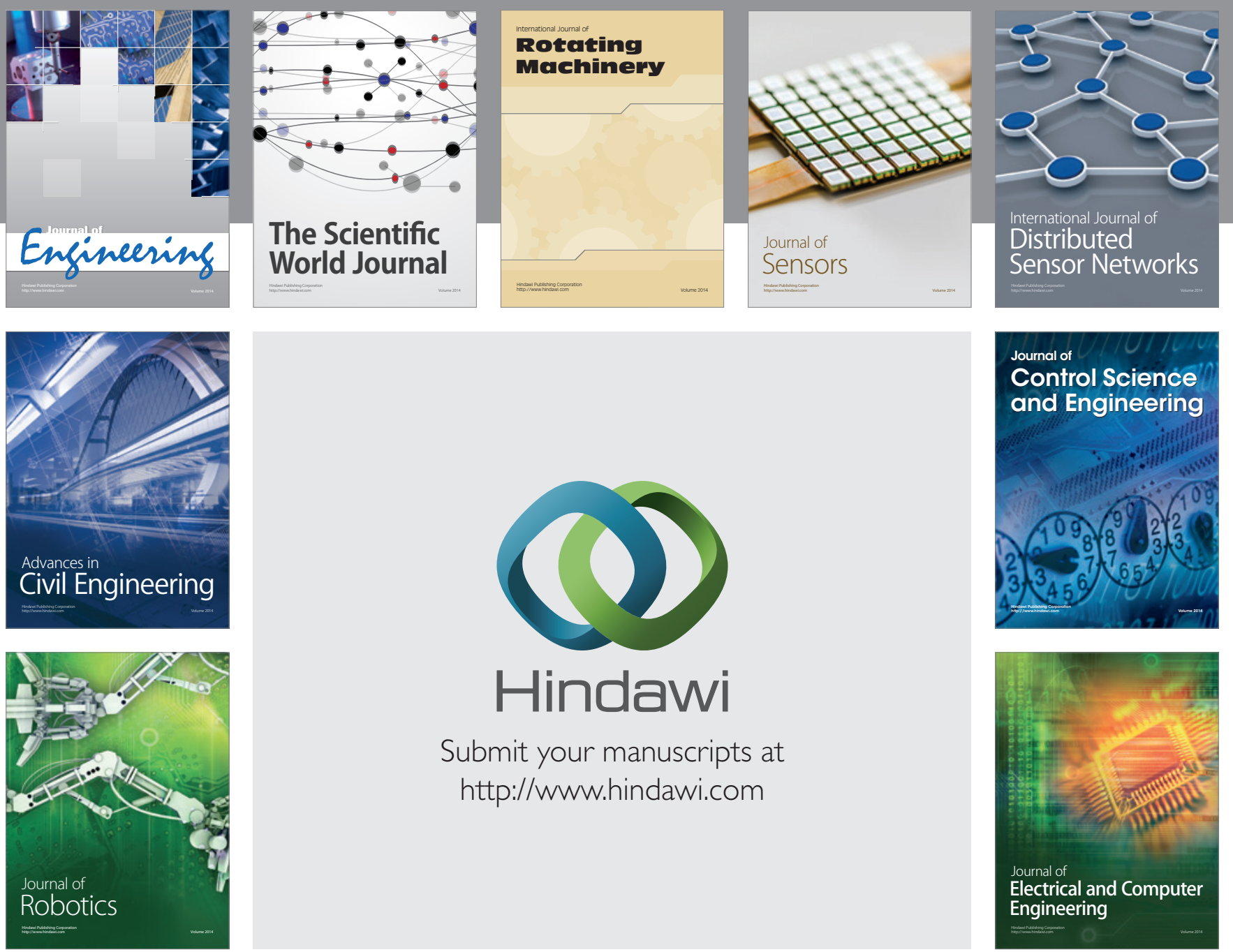

Submit your manuscripts at

http://www.hindawi.com
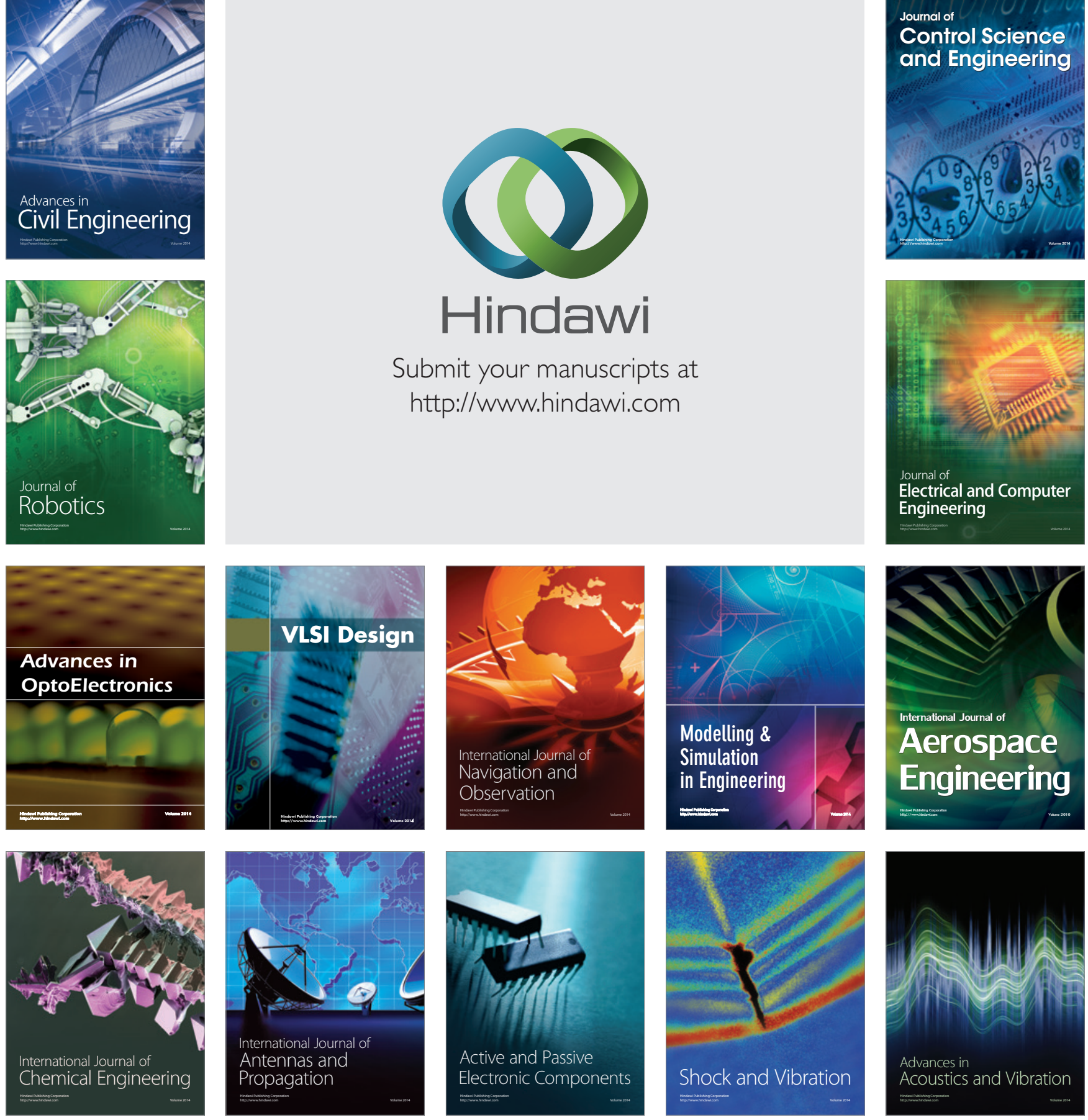